\title{
Species of the genus Chrysotus Meigen, 1824 (Diptera: Dolichopodidae) from Japan, with descriptions of two new species
}

\author{
Oleg P. NEGROBOV ${ }^{1, *}$, Tatsunori KUMAZAWA ${ }^{2}$, Toshihiro TAGO ${ }^{3}$ \& Viktor N. FURSOV ${ }^{4}$ \\ ${ }^{1}$ Voronezh State University, Universitetskaya sq., 1, Voronezh 394006, Russia. \\ ${ }^{2}$ Osaka Museum of Natural History, 1-23, Nagai Park, Higashi-sumiyoshi, Osaka 546-0034, Japan. \\ 3 29-13-101, Motogou, 1-chome, Kawaguchi, Saitama, 332-0011, Japan. \\ ${ }^{4}$ I.I. Schmalhausen Institute of Zoology, Kyiv, Ukraine. \\ *Corresponding author: negrobov@list.ru \\ ${ }^{2}$ Email: pseudocampsicnemus@gmail.com \\ ${ }^{3}$ Email: tago-ke@za2.so-net.ne.jp \\ ${ }^{4}$ Email: ufensia@gmail.com \\ ${ }^{1}$ urn:lsid:zoobank.org:author:18FC9848-2BE3-4809-8A91-070E6C6EB8FE \\ 2 urn:lsid:zoobank.org:author:579148A7-D61D-4D7C-B1BB-8B7573B7FAF6 \\ ${ }^{3}$ urn:1sid:zoobank.org:author:EC82645A-5E91-4977-B0DD-6437FA3976D7 \\ ${ }^{4}$ urn:lsid:zoobank.org:author:FFF72665-7496-4A78-A577-7C10AA998B69
}

\begin{abstract}
Two new species of the genus Chrysotus Meigen, 1824 are described: Ch. masunagai Negrobov, Kumazawa, Tago sp. nov and Ch. saigusai Negrobov, Kumazawa \& Tago sp. nov. Chrysotus parilis Parent, 1926 is recorded from Japan for the first time. An identification key to all known species of the genus Chrysotus of Japan is presented together with a tree diagram showing relationships among them.
\end{abstract}

Keywords. Japan, Chrysotus, Dolichopodidae, new species.

Negrobov O.P., Kumazawa T., Tago T. \& Fursov V.N. 2016. Species of the genus Chrysotus Meigen, 1824 (Diptera: Dolichopodidae) from Japan, with descriptions of two new species. European Journal of Taxonomy 197: 1-15. http://dx.doi.org/10.5852/ejt.2016.197

\section{Introduction}

The cosmopolitan genus Chrysotus is the largest of the subfamily Diaphorinae, including more than 440 species (Grichanov 2014; Wei et al. 2015), of which 91 occur in the Palaearctic Region (Negrobov unpublished data). The Palaearctic species of Chrysotus were revised Negrobov and co-authors in a series of publications (Negrobov 1980; Negrobov \& Maslova 1995; Negrobov et al. 2000, 2003; Maslova et al. 2011). In the Oriental region of China more than one hundred species of the genus Chrysotus are known (Wei 2012; Wei et al. 2015; Liu et al. 2013, 2015).

There are few morphological differences between the species of the genus, but most species can be well distinguished by the structure of the apex of the phallus. Negrobov et al. (2000) published the most 
recent keys of the Palaearctic species of the genus. A key, with 28 species from China, to the males of the genus was also published by Yang et al. (2011).

Meanwhile, only a few studies on the species of the genus in Japan are available (Saigusa 2008). Masunaga (2014) listed only 3 species: Chrysotus cilipes Meigen, 1824, Ch. nudisetus Negrobov \& Maslova, 1995 and Ch. pulchellus Kowarz, 1874. The record of Chrysotus pulchellus for Japan probably belongs to the new species Ch. masunagai sp. nov. described herein. Recently, two species of the genus have been recorded, Ch. tagoi Negrobov, Maslova \& Fursov, 2015 and Ch. kumazawai Negrobov, Maslova \& Fursov, 2015 (Negrobov et al. 2015), but it is assumed that there are more species present in Japan. Here, we present additional records of the genus from Japan, including two new species.

\section{Material and methods}

Specimens were collected by Dr. V.N. Fursov (Schmalhausen Institute of Zoology of the National Academy of Sciences Ukraine) and Mr. T. Tago from Japan.

Holotypes of the new species are deposited in the Osaka Museum of Natural History (OMNH, Japan) and the Zoological Institute of the Russian Academy of Sciences (ZIN, Saint Petersburg, Russia), and some of the paratypes are housed in the collections of the Schmalhausen Institute of Zoology of the National Academy of Sciences Ukraine (IZU), the Osaka Museum of Natural History (OMNH, Japan) and the Voronezh State University (VSU, Russia). We follow Cumming \& Wood (2009) for the terminology. Male terminalia were treated in $10 \% \mathrm{KOH}$ and glycerol for observing genital structures.

Relationships among species were investigated using a tree-diagram constructed in the TNT program (Goloboff et al. 2003). Characters were selected on the basis of their diagnostic value in the key of the genus Chrysotus. All 20 characters were equally weighted. Character polarity was based on outgroup comparison, with the most plesiomorphic state indicated by " 0 " and the apomorphic state indicated by "1" or "2" according to Capellari (2013). The following characters were investigated:

1. Face narrower than the length between ocellar bristles or equal (0). Face wider than the length between ocellar bristles (1).

2. Postpedicel higher than long (0). Postpedicel longer than height (1).

3. Arista subapical (0). Arista apical (1).

4. Palpus brown (0). Palpus pale (1).

5. Lower postocular setae pale (0). Lower postocular setae black (1).

6. Fore coxae dark (0). Fore coxae yellow at distal part (1).

7. Fore coxae with dark hairs (0). Fore coxae with white or yellow hairs (1).

8. Fore femur mostly dark (0). Fore femur yellow (1).

9. Mid femur dark (0). Mid femur yellow (1).

10. Basal part of hind femur dark (0). Basal part of hind femur yellow (1).

11. Hind trochanter dark (0). Hind trochanter yellow (1).

12. Hind tibia brown (0). Hind tibia yellow (1).

13. Hind femora with anteroventral hairs on entire length of femur (0). Hind femora without anteroventral hairs on entire length of femur (1).

14. Hind tibia with short erect anteroventral hairs at lateral side, their length approximately equal to the diameter of tibia (0). Hind tibia without short erect anteroventral hairs at lateral side (1).

15. First segment of hind tarsus with short erect hairs (0). First segment of hind tarsus without short erect hairs (1).

16. Apical part of $\mathrm{CuA}_{1}$ approximately in 2.5 times longer than $\mathrm{dm}-\mathrm{cu}(0)$. Apical part of $\mathrm{CuA}_{1}$ less than in 2.5 times longer than dm-cu (1).

17. Abdomen metallic green (0). Abdomen purple or blue (1). 
Table 1. Morphological characters matrix of the Chrysotus species from Japan.

\begin{tabular}{|c|c|c|c|c|c|c|c|c|c|c|c|c|c|c|c|c|c|c|c|c|}
\hline & \multicolumn{20}{|c|}{ Morphological characters } \\
\hline Species & 1 & 2 & 3 & 4 & 5 & 6 & 7 & 8 & 9 & 10 & 11 & 12 & 13 & 14 & 15 & 16 & 17 & 18 & 19 & 20 \\
\hline Ch. cilipes Meigen, 1824 & 0 & 0 & 0 & 1 & 0 & 1 & 1 & 1 & 1 & 0 & 1 & 1 & 0 & 0 & 0 & 0 & 0 & 1 & 2 & 0 \\
\hline Ch. laesus (Wiedemann, 1817) & 1 & 0 & 1 & 0 & 0 & 0 & 1 & 0 & 0 & 1 & 0 & 0 & 1 & 1 & 1 & 1 & 1 & 0 & 0 & 2 \\
\hline Ch. masunagai sp. nov. & 0 & 1 & 0 & 1 & 0 & 1 & 0 & 0 & 1 & 0 & 1 & 0 & 0 & 0 & 0 & 0 & 0 & 1 & 2 & 1 \\
\hline Ch. nudisetus Negrobov \& Maslova, 1995 & 0 & 0 & 0 & 0 & 1 & 0 & 0 & 0 & 0 & 1 & 0 & 1 & 1 & 1 & 1 & 0 & 0 & 0 & 2 & 0 \\
\hline Ch. parilis Parent, 1926 & 0 & 0 & 0 & 1 & 0 & 1 & 1 & 1 & 1 & 0 & 1 & 1 & 1 & 1 & 1 & 0 & 0 & 1 & 2 & 1 \\
\hline Ch. saigusai sp. nov. & 0 & 0 & 0 & 0 & 0 & 1 & 0 & 0 & 0 & 1 & 1 & 1 & 0 & 0 & 0 & 0 & 0 & 0 & 2 & 0 \\
\hline Ch. tagoi Negrobov et al., 2015 & 0 & 0 & 0 & 0 & 0 & 1 & 0 & 1 & 1 & 0 & 1 & 1 & 1 & 0 & 0 & 0 & 0 & 0 & 2 & 0 \\
\hline Ch. kumazawai Negrobov et al., 2015 & 0 & 0 & 0 & 1 & 0 & 1 & 0 & 0 & 0 & 1 & 1 & 1 & 1 & 0 & 0 & 0 & 0 & 1 & 1 & 1 \\
\hline
\end{tabular}

18. Epandrium in the basal part without small projection (0). Epandrium in the basal part with small projection (1).

19. Apical half of surstylus with two thickened triangular bristles (0). Apical half of surstylus with one thickened triangular bristle (1). Apical half of surstylus without thickened triangular bristles (2).

20. Phallus with two lateral processes at apex (0). Phallus with one lateral process at apex (1). Phallus without lateral processes at apex (2).

\section{Results}

\section{Taxonomic descriptions}

Class Hexapoda Blanville, 1816

Order Diptera Linnaeus, 1758

Family Dolichopodidae Latreille, 1809

Genus Chrysotus Meigen, 1824

We found the following six species in the collection of Mr. T. Tago and of the Schmalhausen Institute of Zoology of National Academy of Sciences Ukraine, including a species new to Japan and two species new to science.

Chrysotus cilipes Meigen, 1824

\section{Material examined}

JAPAN: 9 ổ, Saitama Prefecture, Misato City, Edogawa river bank, 9 Aug. 2008, 15 May 2010, leg. T. Tago.

\section{Distribution}

Western Europe, Abchazia, Afghanistan, Armenia, Azerbaijan, China, Japan, Kazakhstan, Korea, Mongolia, Turkey, Ukraine and Russia (Leningrad, Novgorod, Pskov, Moscow, Voronezh, Adygea, Kabardino-Balkaria, Krasnodar, Rostov, Tomsk, Altai, Krasnoyarsk, Baikal, Transbaikalia, Yakutia, Amur, Maritime Territory). There are a few records of the species in Japan (Negrobov et al. 2008; Masunaga 2014). 
Chrysotus laesus (Wiedemann, 1817)

\section{Material examined}

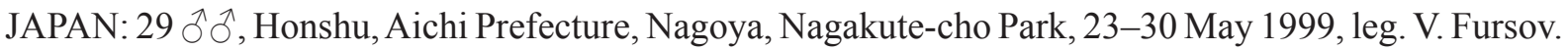

\section{Distribution}

Western Europe, Armenia, Georgia, Japan and Russia (Karelia, Saint Petersburg, Pskov, Yaroslavl, Moscow, Ryasan, Bashkiria, Tatarstan, Kursk, Lipetsk, Voronezh, Krasnodar, Adygea, North Caucasus, Orenburg, Omsk, Tomsk, Altai, Krasnojarsk, Irkutsk, Buryatia, Yakutia, Amur).

Chrysotus nudisetus Negrobov \& Maslova, 1995

Chrysotus sp. 3t - Tago 2010: 44.

\section{Material examined}

JAPAN: 1 ðె, Saitama Prefecture, Misato City, Edogawa river bank, 9 Aug. 2008, leg. T. Tago; 1 ð, Chiba Prefecture, Nagareyama City, Ichinoya, 30 Sep. 2008, leg. T. Tago; 1 §, Saitama Prefecture, Hidaka City, Yokote, 12 Jul. 2009, leg. T. Tago; 1 §̂, Saitama Prefecture, Ootaki, Chichibu City, Mameyakibashi, 7 Aug. 2010, leg. T. Tago.

\section{Distribution}

Japan and Russia: Sakhalin, Primorye, Khabarovsk, Magadan, Chukotka. The species was described from Japan and the Far East of Russia by Negrobov \& Maslova (1995).

\section{Chrysotus parilis Parent, 1926}

\section{Material examined}

JAPAN: Saitama Prefecture, Misato City, Edogawa river bank, 9 Aug. 2008 (3 ふぇ, 2 q $\uparrow), 13$ Oct. 2008

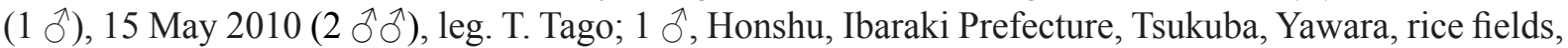
16 Jul. 1997, leg.V. Fursov; 1 Õ, Honshu Aichi Prefecture, Nagoya, Nagakute-cho Park, 23-30 May 1999, leg. V. Fursov.

\section{Distribution}

China, Japan. The species originally described from China is here recorded for the first time from Japan.

Chrysotus masunagai Negrobov, Kumazawa \& Tago, sp. nov. urn:Isid:zoobank.org:act:CA904F5D-F488-4B95-B043-0D598C014071

\section{Figs 1, 5A}

Chrysotus sp. 2t - Tago 2010: 43.

\section{Diagnosis}

Face narrow; postpedicel small; lower postocular setae white; fore coxa with black hairs; femora mostly yellow; mid tibia with 2 anterodorsal and 2 posterodorsal setae; hind femur and with long setae, hind tibia with short hairs; phallus with two lateral processes on tip.

\section{Etymology}

The species is named after the famous dipterologist Dr. Kazuhiro Masunaga from Japan. 


\section{Material examined}

\section{Holotype}

JAPAN: 1 O๊̊, Ibaraki Prefecture, Tsukuba, Yawara, 16 Jun. 1997, leg. V. Fursov (ZIN, Russia).

\section{Paratypes}

JAPAN: 1 \, labeled, Saitama Prefecture, Misato City, Edogawa river bank, 13 Oct. 2008, leg. T. Tago;

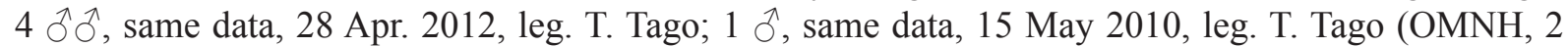
paratypes VSU).

\section{Description}

\section{Male}

MEASUREMENTs. Body length: 1.3-1.4 mm, wing length: $1.4-1.5 \mathrm{~mm}$.

HEAD. Frons green with purple tinge, without pollen. Face narrow, its width narrower than the width between ocellar bristles in lower part. Frons green at the top, with pollinosity at the bottom. Antenna black, postpedicel small, triangular, length 1.3 times greater than height. Arista subapical, with short hairs. Length of arista more than two times longer than length of postpedicel. Proboscis and palpus brown with black hairs without pollen. Lower postocular setae pale.

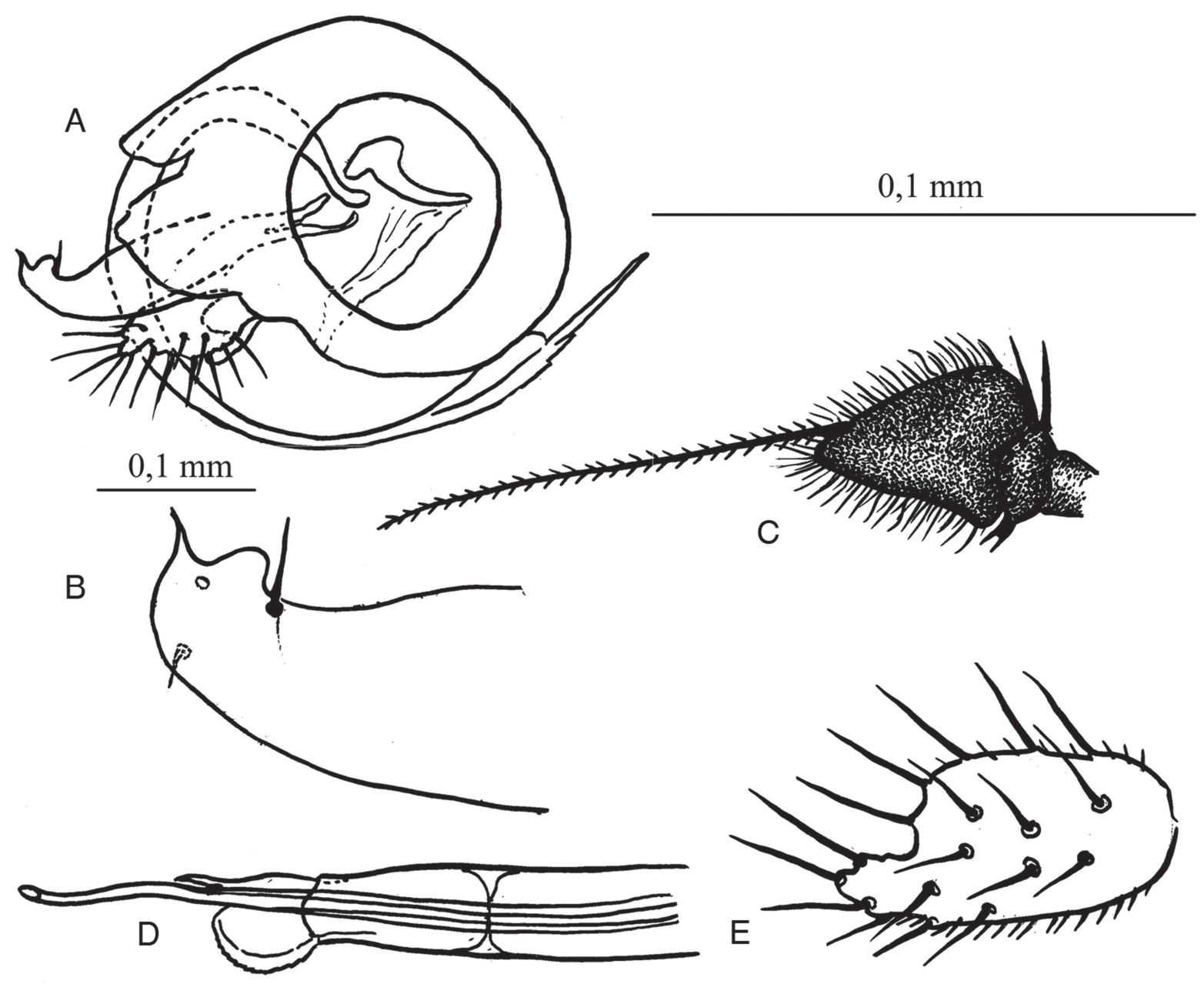

Fig. 1. Chrysotus masunagai Negrobov, Kumazawa \& Tago sp. nov., Ô, paratype, coll. 28 Apr. 2012. A. Hypopygium, lateral view. B. Apex of surstylus, lateral view. C. Antenna. D. Apex of phallus, lateral view. E. Cerci, lateral view. 
Thorax. Metallic green, scutum with bronze tinge and without pollen. Pleura with pollen, propleuron with 1-2 setae. 5 pairs of strong dorsocentral setae. Acrostichal setae long, irregular 6-7 pairs, arranged in two rows. Scutellum with 2 long and 2 short lateral setae.

LEG. Fore coxa yellowish brown, mid and hind coxa dark; femora mostly yellow, except dorsal surfaces of fore femur, middle part of the mid femur and apical third part of the hind femur dark; fore and mid tibiae yellow, hind tibia dark; tarsi yellow except hind tarsus and apical parts of fore and mid tarsus dark. All coxae with dark hairs and setae. Fore femur with long white anteroventral hairs, length approximately equal to the width of femur. Fore tibia with 1 anterodorsal seta and short posteroventral hairs. Ratio of fore tibia and tarsus (from 1 to 5) 2.6: 1.5: 0.6: 0.5: 0.3: 0.4. Mid femur with a short preapical seta. Mid tibia with 2 anterodorsal and 2 short posterodorsal setae. Ratio of mid tibia and tarsus (from 1 to 5) 3.4: 1.6: 0.8: 0.6: 0.4: 0.3. Hind femur with several long preapical setae and short anteroventral hairs on entire length femur. Hind tibia with 3-4 short anterodorsal setae and short erect anteroventral hairs, its length approximately equal to the diameter of tibia. First segment of hind tarsus with short erect hairs. Ratio of hind tibia and tarsus (from 1 to 5) 3.7: 1.2: 1.0: 0.6: 0.4: 0.3 .

WING. Hyaline with dark veins; $\mathrm{R}_{4+5}$ and $\mathrm{M}_{1+2}$ parallel at apex. Length of costal section between $\mathrm{R}_{4+5}$ and $\mathrm{M}_{1+2}$ more than 2 times longer than that between $\mathrm{R}_{2+3}$ and $\mathrm{R}_{4+5} ; m$-cu distinctly shorter than apical part of $\mathrm{CuA}_{1}$. Halter and cilia on lower calypter yellow.

AвDOMEN. Metallic green, grey pollinose laterally, covered with black hairs. Epandrium oval in the basal part of the oval; apical part of surstylus bent. Apex of phallus with two short lateral processes, left process is rounded. Cercus with brown hairs, top of the left side with long processes.

\section{Female}

Unknown.

\section{Addition to the key}

In the key to the Palearctic species of Chrysotus (Negrobov et al. 2000), the new species Chrysotus masunagai sp. nov. runs to Chrysotus verralli Parent, 1923 and can be distinguished from the latter by following characters:

45. Femora almost yellow; dorsal side of fore femur, middle part of the mid femur and apical part of the hind femur dark. Hind trochanter yellow

Ch. masunagai Negrobov, Kumazawa, Tago sp. nov.

- Femora dark. Hind trochanter black. England Ch. verralli Parent, 1923

Chrysotus saigusai Negrobov, Kumazawa \& Tago sp. nov. urn:1sid:zoobank.org:act:D4B29EEA-1EF5-4210-A383-94EFE3ED35EA

Figs 2, 5B

Chrysotus sp. 1t - Tago 2010: 43.

\section{Diagnosis}

Face narrow, width in lower part less than distance between ocellar bristles; antenna black; postpedicel transverse-oval, with a triangular tip; lower postocular setae white; fore coxa with black hairs; femora mainly green-brown; mid tibia with 2 anterodorsal and 2 posterodorsal setae; hind femur with long setae, hind tibia with short hairs; phallus with two lateral processes on tip. 


\section{Etymology}

The species is named after the famous dipterologist Dr. Toyohei Saigusa from Japan.

\section{Material examined}

\section{Holotype}

JAPAN: $\widehat{O}$, Honshu, Aichi Prefecture, Kasugai, Univ. Experim. Farm, on grass near ponds, 19 Jun. 2004, leg. V. Fursov (ZIN).

\section{Paratypes}

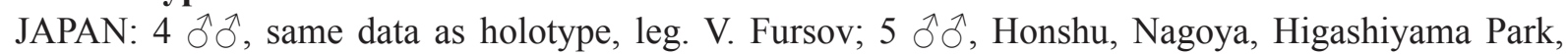
oak forest, 2 May 1999, leg. V. Fursov; $14 \widehat{\delta} \widehat{\partial}$, Honshu, Nagoya, Higashiyama Park, oak forest, 11 Aug. 1999, leg. V. Fursov; 1 ô, Ibaraki Prefecture, Tsukuba, Sakuragaoka, swept grass near forest,

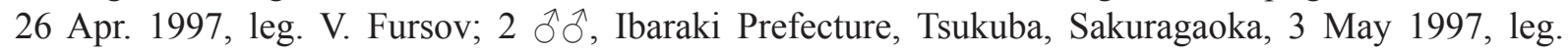

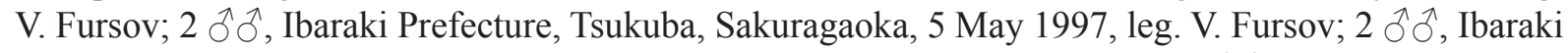
Prefecture, Tsukuba, Yaware, near rice fields, 17 Jun. 1997, leg. V. Fursov; $4 \hat{\delta} \hat{\jmath}$, Ibaraki Prefecture,

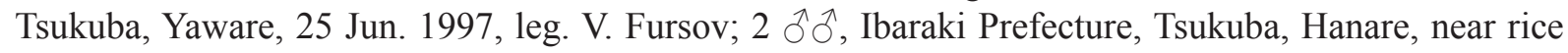

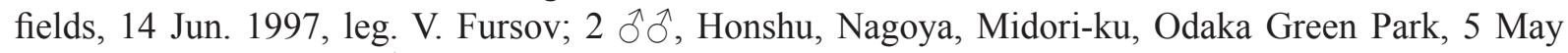
1999, leg. V. Fursov; 1 đ̆, Honshu, Nagoya, Nissin-shi, 5 Apr. 1999, leg. V. Fursov (IZU, VSU, ZIN);

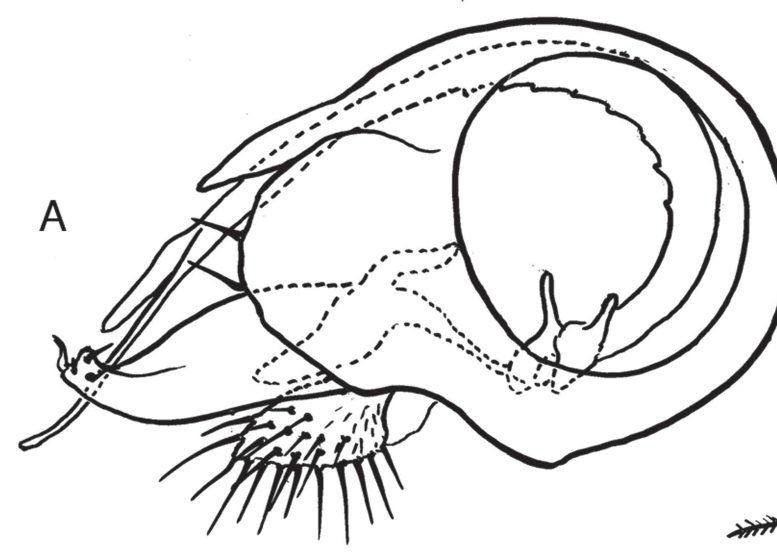

B

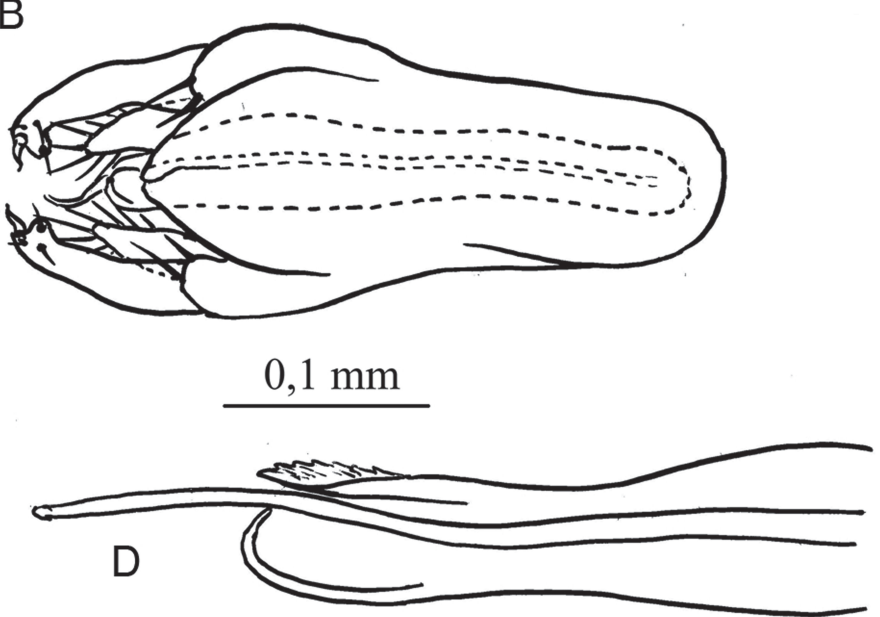

$0,1 \mathrm{~mm}$

C

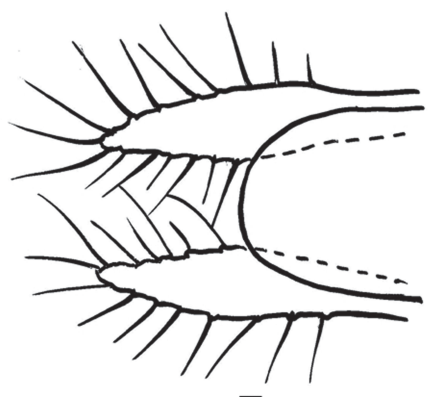

$\mathrm{E}$

Fig. 2. Chrysotus saigusai Negrobov, Kumazawa \& Tago sp. nov., đ, paratype, coll. 8 Jul. 2012. A. Hypopygium, lateral view. B. Hypopygium, ventral view. C. Antenna. D. Apex of phallus, lateral view. E. Cerci, ventral view. 


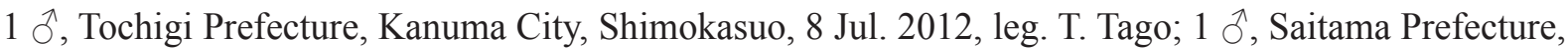
Saitama City, Akigase Park, Sakura wood, 1 Oct. 2011, leg. T. Tago (OMNH, Japan); 1 đ, Kuril Islands, island Kunashir, Alekhine, 8-12 Aug. 1984, leg. Kirejtshuk (ZIN).

\section{Description}

\section{Male}

MEASUREMENTs. Body length: $1.2-1.3 \mathrm{~mm}$, wing length: $1.2-1.3 \mathrm{~mm}$.

Head. Frons green with purple tinge, without pollen. Face narrow, its width narrower than the width between ocellar bristles in lower part. Frons green at the top, with pollinosity on the bottom. Antenna black, postpedicel small, a right-angled triangular, its length about equal to its height. Arista subapical, with short hairs. Length of arista approximately five times longer than length of postpedicel. Proboscis and palpus brown with black hairs without pollen. Lower postocular setae pale.

Thorax. Metallic green, scutum with bronze tinge and without pollen. Pleura with pollen, propleuron with 1-2 setae. 5 pairs of strong dorsocentral setae. Acrostichal setae long, irregular 6-7 pairs, arranged in two rows. Scutellum with 2 long and 2 short lateral setae.

LEG. All coxae dark; femora mostly dark, except apical part of fore femur, apical and basal part of mid femur and basal part of hind femur yellow; trochanters yellow or yellowish-brown; fore and mid tibiae yellow, hind tibia yellowish-brown; most part of mid and hind tarsi yellow, basal parts hind tarsus yellowish-brown. Coxae with dark hairs and setae. Fore femur with 3 long preapical setae. Fore tibia with 1 anterodorsal seta and short posteroventral hairs. Fore tarsus with short hairs. Ratio of fore tibia and tarsus (from 1 to 5) 2.8: 1.7: 0.7: 0.5: 0.4: 0.5. Mid femora with 3 short preapical setae and short anteroventral hairs. Mid tibia with 2 anterodorsal and 2 short posterodorsal setae. Ratio of mid tibia and tarsus (from 1 to 5) 3.8: 2.1: 1.0: 0.7: 0.5: 0.4. Hind femora with 4 long preapical setae and short anteroventral hairs on entire length of femur. Hind tibia with 4 short anterodorsal, 3 posterdorsal setae and short erect anteroventral hairs, their length approximately equal to the diameter of tibia. First segment of hind tarsus with short erect hairs. Ratio of hind tibia and tarsus (from 1 to 5) 4.4: 1.5: 1.2: 0.7: $0.5: 0.4$.

WING. Hyaline with dark veins; $\mathrm{R}_{4+5}$ and $\mathrm{M}_{1+2}$ slightly divergent at apex. Length of costal section between $\mathrm{R}_{4+5}$ and $\mathrm{M}_{1+2}$ about twice longer than that between $\mathrm{R}_{2+3}$ and $\mathrm{R}_{4+5} ; m-c u$ distinctly shorter than apical part of $\mathrm{CuA}_{1}$. Halter and cilia on lower calypter yellow.

AвDOMEN. Metallic green, pollinose laterally, covered with black hairs. Epandrium oval in the basal part with the small projection; apical tip of surstylus bent. Phallus with two lateral processes at apex. Cercus oval with black hairs.

\section{Female}

Unknown.

\section{Addition to the key}

In the key to the Palearctic species of Chrysotus (Negrobov et al. 2000), the new species Chrysotus saigusai Negrobov, Kumazawa \& Tago sp. nov. runs to Chrysotus defensus Negrobov \& Maslova, 2000 and can be distinguished from the latter by the following characters:

58. Basal part of hind femur and hind trochanter black. The phallus before the apex with two long dorsal processes. Caucasus Ch. defensus Negrobov \& Maslova, 2000

- Basal part of hind femur and hind trochanter yellow. The phallus before the apex with short lateral processes Ch. saigusai Negrobov, Kumazawa \& Tago sp. nov. 


\section{Key to the males of Japanese Chrysotus}

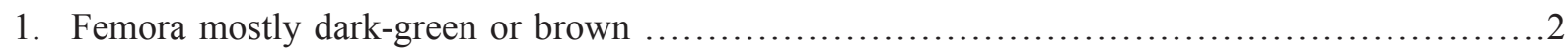

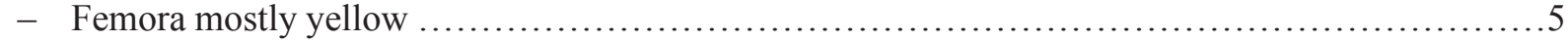

2. Postocular setae black (Fig. 3A-C) ....................h. nudisetus Negrobov \& Maslova, 1995

- Postocular setae pale

A
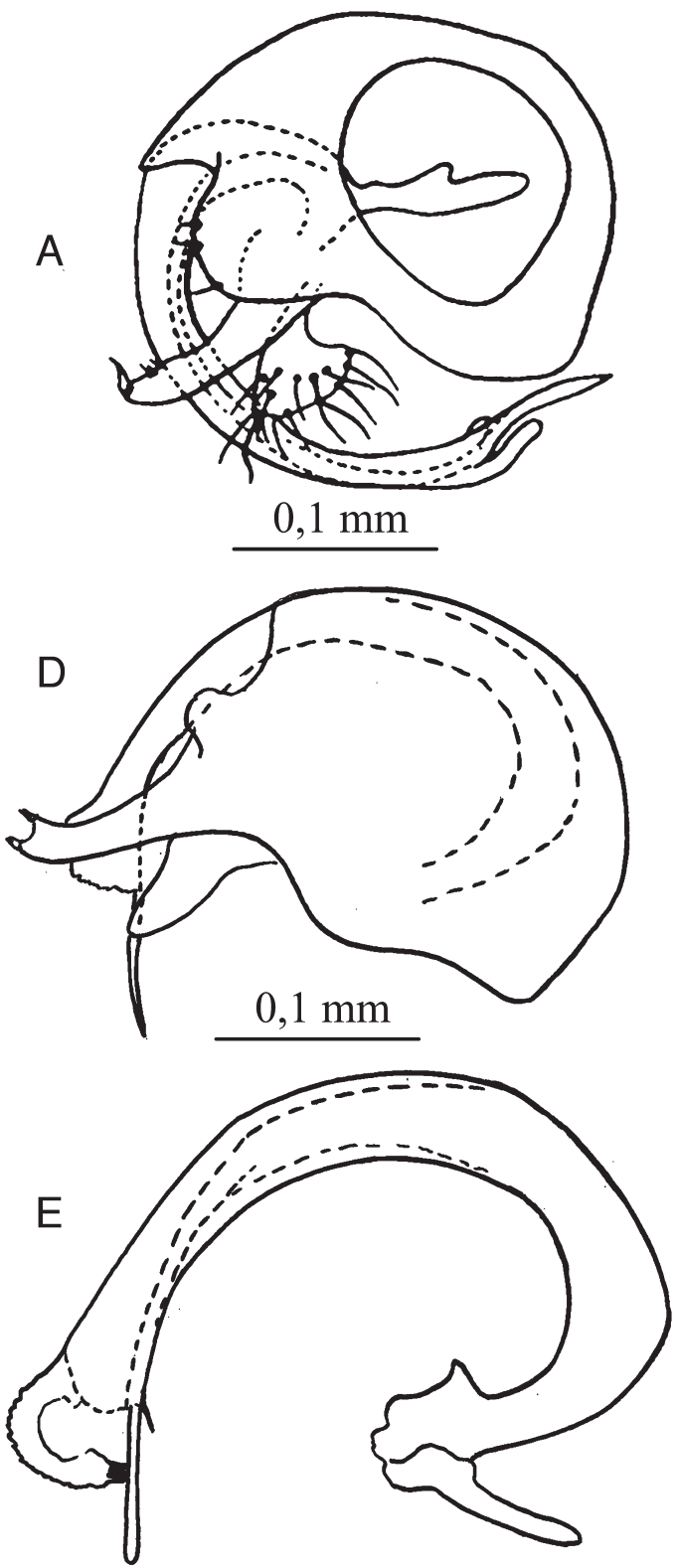

B

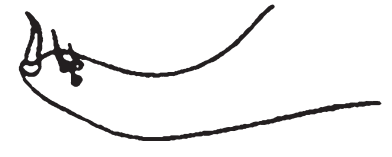

C
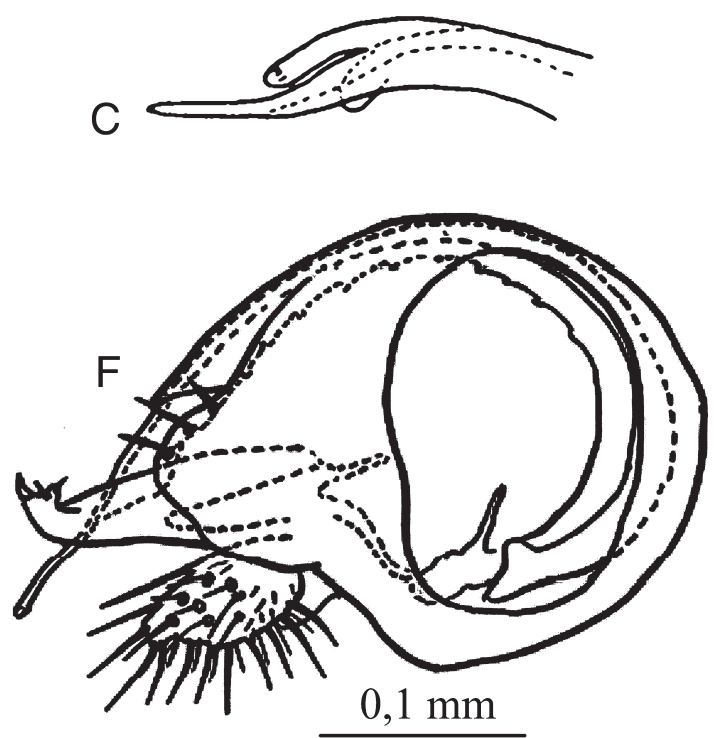

$\mathrm{G}$

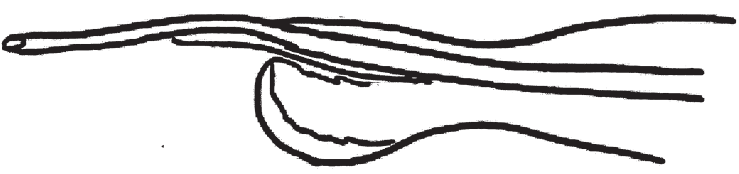

Fig. 3. A-C. Chrysotus nudisetus Negrobov \& Maslova, 1995, §, paratype, Russia (Sakhalin). A. Hypopygium, lateral view. B. Surstylus, ventral view. C. Apex of phallus, lateral view. D-E. Chrysotus laesus (Wiedemann, 1817), Russia (European part). D. Hypopygium, lateral view. E. Phallus, lateral view. - F-G. Chrysotus kumazawai Negrobov, Maslova \& Fursov, 2015, §̊, paratype, coll. 20 Jul. 1997 by V. Fursov. F. Hypopygium, lateral view. G. Apex of phallus, lateral view. 
3. Face wide, more than 2 times wider than the length between ocellar bristles. Thorax and abdomen with purple tingle. Postpedicel large, approximately 2 times wider than long (Fig. 3D-E)

Ch. laesus (Wiedemann, 1817)

- Face narrow, narrower than the length between ocellar bristles. Thorax and abdomen green.

Postpedicel small, approximately as long as wide

4. Postpedicel triangular apically. Surstylus approximately 1.5 times longer than cercus. Apicoventral epandrial lobe well developed, broad oval, without excavation

Ch. saigusai Negrobov, Kumazawa \& Tago sp. nov.

- Postpedicel oval apically. Surstylus approximately equal to cercus. Apicoventral epandrial lobe not developed, with excavation at apex (Fig. $3 \mathrm{~F}-\mathrm{G})$

Ch. kumazawai Negrobov, Maslova \& Fursov, 2015

5. Fore coxae with black hairs

- Fore coxae with white hairs
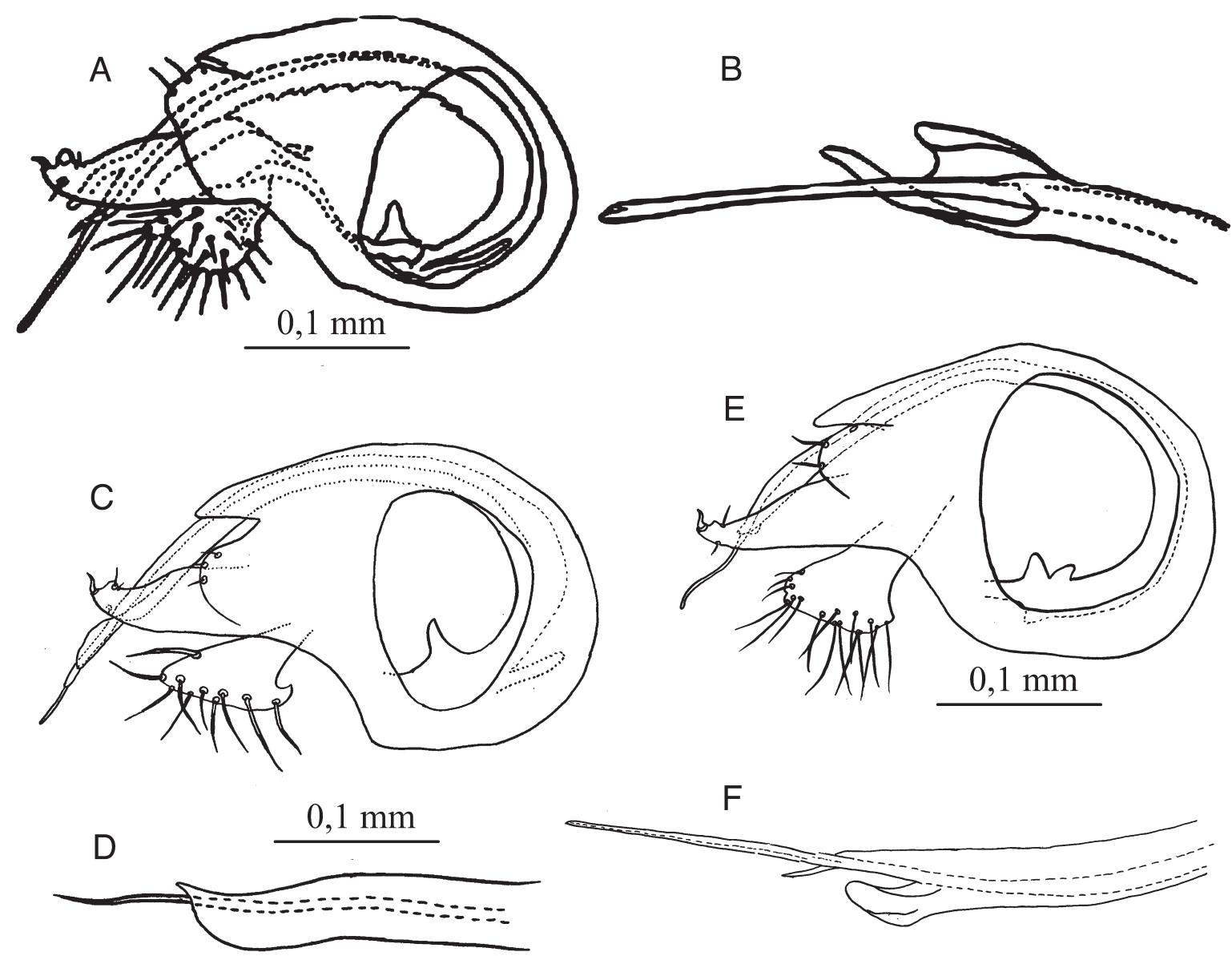

Fig. 4. A-B. Chrysotus tagoi Negrobov, Maslova \& Fursov, 2015, đ̃, paratype, Japan (Honshu, Ibaraki Pref., Tsukuba), coll. 16. Jul. 1997 by V. Fursov. A. Hypopygium, lateral view. B. Apex of phallus, lateral view. - C-D. Chrysotus parilis Parent, 1926, Russia (Primorje). C. Hypopygium, lateral view. D. Apex of phallus, lateral view. - E-F. Chrysotus cilipes Meigen, 1824, Russia (Primorje). E. Hypopygium, lateral view. F. Apex of phallus, lateral view. 
6. Postpedicel longer than wide. Dorsal part of fore femora, middle femora in the middle part and apical third of hind femora dark. Phallus with oval process at apex on the left side .........

Ch. masunagai Negrobov, Kumazawa, Tago sp. nov.

- Postpedicel small, approximately as long as wide. Hind femora with dark spot at apex, the rest of femora yellow. Phallus with claw-shaped process at apex on the left side (Fig. 4A-B)

Ch. tagoi Negrobov, Maslova \& Fursov, 2015

7. Hind tibia without long erect hairs. Hind tibia at apex without group of ventral hairs. Postpedicel large, triangular at apex (Fig. 4C-D)

Ch. parilis Parent, 1926

- Hind tibiae and hind tarsi with long erect hairs, longer than tibia width. Hind tibia at apex with group of ventral hairs. Postpedicel small, oval apically (Fig. 4E-F)

Ch. cilipes Meigen, 1824

\section{Cladistic analyses}

According to Capellari (2013), the absence of a small projection in the basal part of the epandrium represents the plesiomorphic character state. The combination of this character state with such character states as pale palpus, dark fore coxae, yellow hind tibia with short erect anteroventral hairs and short erect hairs on the first segment of hind tarsus separate the group of Ch. saigusai and Ch. tagoi from all other Japanese Chrysotus (Fig. 6). The species Ch. saigusai can be separated from Ch. tagoi by having anteroventral hairs on the entire length of find femora and mostly dark fore femora.

The presence of the epandrial projection is the typical character states of the species Ch. cilipes, Ch. parilis and Ch. masunagai sp. nov., they are, however, included in the group with Ch. saigusai

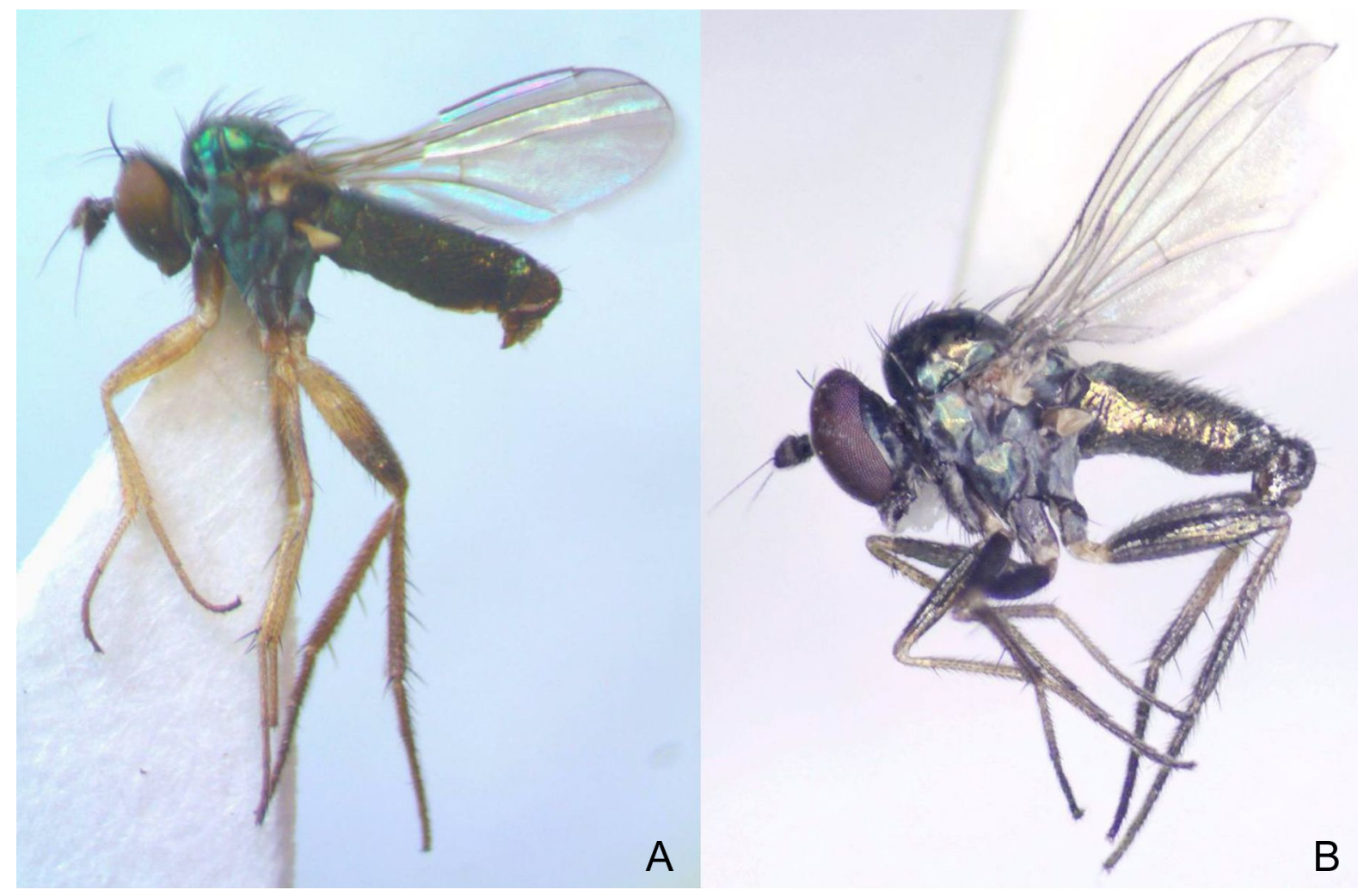

Fig. 5. Male habitus, lateral view. A. Chrysotus masunagai Negrobov, Kumazawa \& Tago sp. nov., ô, paratype, coll. 15 May 2010. B. Chrysotus saigusai Negrobov, Kumazawa \& Tago sp. nov., ô, paratype, coll. 8 Jul. 2012. 
sp. nov. and Ch. tagoi on the basis of the characters of face width, position of arista, cooler of postocular bristles, fore coxa, hind trochanter and morphology of $\mathrm{CuA}_{1}$. Concerning the distinctive characters of the group including Ch. cilipes, Ch. parilis and Ch. masunagai sp. nov., in addition to the above mentioned, the following character states can be ascribed: yellow middle femora and dark basal part of hind femur. The morphological similarity between Ch. cilipes and Ch. parilis is sufficiently significant, while the relationship with $C h$. masunagai sp. nov. is unstable.

The species Ch. laesus, Ch. nudisetus and Ch. kumazawai compose the group with the least stable internal connections. Their association is based on the similarity of color of fore, middle and hind femora and the absence of the anteroventral hairs on entire length of hind femur.

\section{Discussion}

The genus Chrysotus is paraphyletic or possibly polyphyletic within the subfamily Diaphorinae (Capellari \& Amorim 2012). Bickel (2010) considers species of Chrysotus as various small-size Diaphorinae species, mostly with inadequate description. Knowledge on the phylogenetic relationships of the genus is poor. Therefore, it is important to investigate phylogenetic relationships of Chrysotus species using both morphological and biogeographical data.

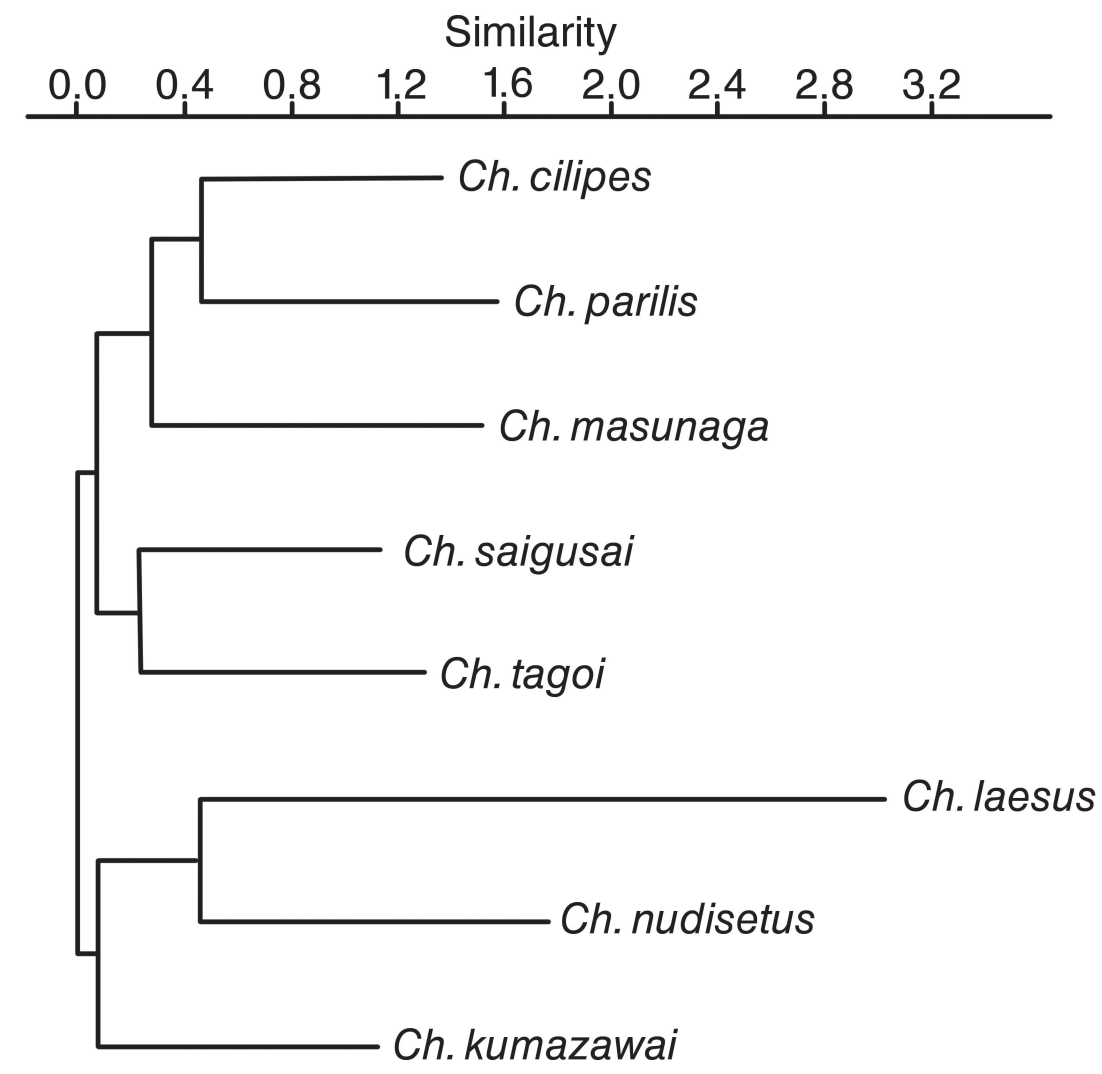

Fig. 6. Consensus cladistic tree of 6 equally parsimonious trees obtained from 20 morphological characters for the Chrysotus Meigen, 1824 species from Japan. 
Eight species of the genus Chrysotus have been reported from the studied country and four of them are endemic, while the others have trans-Palearctic (Ch. cilipes, Ch. laesus, Ch. parilis) and East-Palearctic (Ch. nudisetus) distributions.

The present cladistic analysis was made in two ways. When we consider the characteristics used in the Palearctic keys of the genus, we were considering the possible relationship between the endemic and trans-Palearctic species, thus inserting the endemic species in the general scheme.

The morphology of the genus Chrysotus is relatively variable, and the most important diagnostic characters are the morphology of the apical part of the phallus, the color of the legs and the form of the postpedicel. It should be noted that the use of the full list of characteristics does not allow for allocating the endemic species in a separate cluster on any of the cladistic trees.

The cladistic analysis was carried out on the basis of a different combination of characters. It allowed for the identification of groups of characters that separate the Japanese endemic species from the transPalearctic species. This group of characters includes color of coxae and trochanter, ratio of apical part of $\mathrm{CuA}_{1}$ and $\mathrm{dm}-\mathrm{cu}$, the presence of erect hairs at hind tibia and the first segment of hind tarsus and morphology of hypopygium. Most of the cladistic trees that were based on this combination of characters demonstrated the allocation of two clusters comprising pairwise Ch. masunagai sp. nov. Ch. kumazawai and Ch. saigusai sp. nov. - Ch. tagoi. However, other stable regularities should also be noted, which is shown in a number of cladistic trees. The clusters of endemic species often have been associated with Palearctic species. So Ch. masunagai sp. nov. - Ch. kumazawai have been associated with Ch. parilis and Ch. saigusai sp. nov.- Ch. tagoi have been associated with Ch. cilipes. None of the combinations of characters showed a clear allocation of these endemic species.

Most of the characteristics, including head morphology and color of legs, which are used for the diagnosis of the Palearctic species, cannot be used for the Japanese species. Thus, further study of the phylogenic relationships of Chrysotus species should be carried out, using a wider range of species, including both trans-Palearctic and endemic species.

\section{Acknowledgements}

We express our gratitude to Dr. L. Wei for information about the species of the genus Chrysotus in China, to the assistant of Voronezh University M. Chursina for the parsimony analysis of the species and head of the Laboratory Olga Selivanova for creating the figures. We express our gratitude to Dr. Martin Drake for making available the species of Chrysotus from England. The work was supported by the Russian Foundation for Basic Research, grant No. 14-04-00264-a.

\section{References}

Bickel D. 2010. New World Achradocera in Hawai'i, Tonga, and French Polynesia, with discussion of the genus (Diptera: Dolichopodidae). Bishop Museum Occasional Papers 64: 14-20.

Capellari R. S. 2013. Análise cladística de Diaphorinae (Diptera: Dolichopodidae). Tese de doutorado apressentada a Faculdade de Ciencias e Letras de Ribeirao Preto. Universidade de São Paulo, São Paulo.

Capellari R.S. \& Amorim D.S. 2012. Systematic position of the monotypic Azorean genus Falbouria Dyte with notes on the definition of Chrysotus Meigen (Diptera: Dolichopodidae). Zootaxa 3489: 81-88.

Cumming J.M. \& Wood D.M. 2009. Adult morphology and terminology [Chapter]. In: Brown B.V., Borkent A., Coming J.M., Wood D.M., Woodley N.E. \& Zombado M.F. (eds) Manual of Central American Diptera. Volume 1: 9-50. NRC Research Press, Ottawa. 
Goloboff P., Farris J. \& Nixon K. 2003. Tree analysis using New Technology [online]. Available from http://www.lillo.org.ar/phylogeny/tnt [accessed 25 Nov. 2015]

Grichanov I. Ya. 2014. Alphabetic list of generic and specific names of predatory flies of the epifamily Dolichopodidae (Diptera). Plant Protection News Supplement 14. All Russian Institute of Plant Protection RAAS, St. Petersburg.

Liu R., Wang M. \& Yang D. 2013. Chrysotus Meigen (Diptera, Dolichopodidae) from Tibet with description of four new species. Zootaxa 3717 (2): 169-178. http://dx.doi.org/10.11646/zootaxa.3717.2.3

Liu R., Wang M. \& Yang D. 2015. Chrysotus Meigen (Diptera, Dolichopodidae) from Shanxi, China, with descriptions of two new species. Zoological Systematics 40 (1): 86-92.

Maslova O.O., Negrobov O.P. \& Selivanova O.V. 2011. Fauna of species of genus Chrysotus (Diptera, Dolichopodidae) of Russia. Part 1. Group of species Chrysotus cilipes Meigen and Ch. laesus Wied. Entomologicheskoe obozrenie 110 (1): 464-468. [in Russian]

Masunaga K. 2014. Dolichopodidae. In: Nakamura T., Saigusa T. \& Suwa M. (eds) Catalogue of the Insects of Japan, Vol. 8. Diptera. Part 1, Nematocera-Brachycera: 439-447. Entomological Society of Japan, Fukuoka.

Negrobov O.P. 1980. A revision of palearctic Chrysotus Mg. (Dipt., Dolichopodidae) I: Ch. cilipes $\mathrm{Mg}$ and Ch. laesus Wied. groups. Entomologicheskoe obozrenie 59: 415-420. [in Russian]

Negrobov O.P. \& Maslova O.O. 1995. Revision of palearctic species of genus Chrysotus Mg. (Diptera, Dolichopodidae). Entomologicheskoe obozrenie 74 (2): 456-466. [in Russian]

Negrobov O.P., Maslova O.O. \& Fursov V.N. 2015. New data on the genus Chrysotus Meigen, 1824 (Diptera: Dolichopodidae) from Japan and Russia. Far Eastern Entomologist 293: 10-15.

Negrobov O.P., Maslova O.O. \& Selivanova O.V. 2008. Two species of Chrysotus (Diptera, Dolichopodidae) new to Japan. Dipterists Digest 18: 44.

Negrobov O.P., Tsurikov M.N. \& Maslova O.O. 2000. Revision of the Palaearctic species of the genus Chrysotus Mg. (Diptera, Dolichopodidae), III. Entomologicheskoe obozrenie 79: 227-238. [in Russian]

Negrobov O.P., Tsurikov M.N. \& Maslova O.O. 2003. Revision of palearctic species of genus Chrysotus Mg. (Diptera, Dolichopodidae). IV Entomologicheskoe obozrenie 82 : 223-228. [in Russian]

Saigusa T. 2008. Order Diptera. In: Hirashima Y., Morimoto K. (eds.) Iconographia insectorum Japonicorum colore naturali edita. Vol. III: 255-283. Hokuryūkan, Tokyo. [in Japanese]

Tago T. 2010. Records of 68 species of Dolichopodidae from the Kanto region (Diptera, Dolichopodidae). Hana-abu. 30: 1-96. [in Japanese]

Wei L. 2012. Chrysotus Meigen (Diptera, Dolichopodidae) from China with descriptions of new species. Oriental Insects 46 (1): 30-52. http://dx.doi.org/10.1080/00305316.2012.675659

Wei L., Zhang L. \& Zhou Z. 2015. A review of the genus Chrysotus Meigen (Diptera, Dolichopodidae) from China with definition of papuanus species group. Oriental Insects 48 (3-4): 187-298. http://dx.doi. org/10.1080/00305316.2015.1005960

Yang D., Zhang L., Wang M. \& Zhu Y. 2011. Dolichopodidae. Fauna Sinica: Insecta, 53. Science Press, Beijing. [in Chinese, with English summary] 
Published on: 17 May 2016

Topic editor: Koen Martens

Desk editor: Kristiaan Hoedemakers

Printed versions of all papers are also deposited in the libraries of the institutes that are members of the EJT consortium: Muséum national d'Histoire naturelle, Paris, France; Botanic Garden Meise, Belgium; Royal Museum for Central Africa, Tervuren, Belgium; Natural History Museum, London, United Kingdom; Royal Belgian Institute of Natural Sciences, Brussels, Belgium; Natural History Museum of Denmark, Copenhagen, Denmark. 